\title{
Rates of minor adverse events and health resource utilization postcolonoscopy
}

\author{
Vladimir Marquez Azalgara MDCM MSc${ }^{1}$, Maida J Sewitch PhD², \\ Lawrence Joseph $\mathrm{PhD}^{3}$, Alan N Barkun MDCM FRCPC FACP FACG AGAF MSc ${ }^{2}$
}

\begin{abstract}
V Marquez Azalgara, M Sewitch, L Joseph, AN Barkun. Rates of minor adverse events and health resource utilization postcolonoscopy. Can J Gastroenterol Hepatol 2014;28(11):595-599.
\end{abstract}

BACKGROUND: Little is known about minor adverse events (MAEs) following outpatient colonoscopies and associated health care resource utilization.

OBJECTIVE: To estimate the rates of incident MAE at two, 14 and 30 days postcolonoscopy, and associated health care resource utilization. A secondary aim was to identify factors associated with cumulative 30-day MAE incidence.

METHODS: A longitudinal cohort study was conducted among individuals undergoing an outpatient colonoscopy at the Montreal General Hospital (Montreal, Quebec). Before colonoscopy, consecutive individuals were enrolled and interviewed to obtain data regarding age, sex, comorbidities, use of antiplatelets/anticoagulants and previous symptoms. Endoscopy reports were reviewed for intracolonoscopy procedures (biopsy, polypectomy). Telephone or Internet follow-up was used to obtain data regarding MAEs (abdominal pain, bloating, diarrhea, constipation, nausea, vomiting, blood in the stools, rectal or anal pain, headaches, other) and health resource use (visits to emergency department, primary care doctor, gastroenterologist; consults with nurse, pharmacist or telephone hotline). Rates of incident MAEs and health resources utilization were estimated using Bayesian hierarchical modelling to account for patient clustering within physician practices.

RESULTS: Of the 705 individuals approached, 420 (59.6\%) were enrolled. Incident MAE rates at the two-, 14- and 30-day follow-ups were $17.3 \%$ (95\% credible interval [CrI] $8.1 \%$ to $30 \%), 10.5 \%(95 \%$ CrI $2.9 \%$ to $23.7 \%$ ) and $3.2 \%$ (95\% CrI $0.01 \%$ to $19.8 \%$ ), respectively. The 30-day rate of health resources utilization was $1.7 \%$, with $0.95 \%$ of participants seeking the services of a physician. No predictors of the cumulative 30-day incidence of MAEs were identified.

DISCUSSION: The incidence of MAEs was highest in the $48 \mathrm{~h}$ following colonoscopy and uncommon after two weeks, supporting the Canadian Association of Gastroenterology's recommendation for assessment of late complications at 14 days. Predictors of new onset of MAEs were not identified, but wide CrIs did not rule out possible associations. Although $<1 \%$ of participants reported consulting a physician for MAEs, this figure may represent a substantial number of visits given the increasing number of colonoscopies performed annually.

CONCLUSION: Postcolonoscopy MAEs are common, occur mainly in the first two weeks postcolonoscopy and result in little use of health resources.

Key Words: Colonoscopy; Health services utilization; Minor adverse events; Patient-centred care

\section{Le taux d'événements indésirables mineurs et d'utilisation des ressources de santé après une coloscopie}

HISTORIQUE : On ne sait pas grand-chose des événements indésirables mineurs (ÉIM) qui suivent les coloscopies ambulatoires et de l'utilisation des ressources de santé qui s'y rattachent.

OBJECTIF : Évaluer le taux d'ÉIM deux, 14 et 30 jours après la coloscopie, de même que l'utilisation des ressources de santé s'y rapportant. L'objectif secondaire consistait à déterminer les facteurs associés à l'incidence d'ÉIM cumulatifs au bout de 30 jours.

MÉTHODOLOGIE : Les chercheurs ont mené une étude de cohorte auprès de personnes qui subissaient une coloscopie ambulatoire à l'Hôpital général de Montréal (HGM), au Québec. Avant la coloscopie, des personnes consécutives ont été enrôlées et interviewées. Elles ont donné de l'information sur leur âge, leur sexe, leurs comorbidités, leur utilisation d'antiplaquettaires et d'anticoagulants ainsi que leurs symptômes antérieurs. Les chercheurs ont examiné les rapports d'endoscopie pour connaître l'intervention privilégiée (biopsie, polypectomie). Lors du suivi par téléphone ou par Internet, les chercheurs ont obtenu les données relatives aux ÉIM (douleurs abdominales, gonflements, diarrhée, constipation, nausées, vomissements, sang dans les selles, douleurs rectales ou anales, céphalées, autre) et à l'utilisation des services de santé (visite à l'urgence, rendezvous avec le médecin de première ligne ou le gastroentérologue, consultations avec une infirmière, un pharmacien ou une ligne téléphonique d'urgence). Ils ont évalué le taux d'ÉIM et d'utilisation des ressources de santé au moyen du modèle bayésien hiérarchique pour tenir compte du regroupement de patients au sein des pratiques des médecins.

RÉSULTATS : Sur les 705 personnes abordées, 420 (59,6\%) ont participé. Les taux d'ÉIM au suivi au bout de deux, 14 et 30 jours s'élevaient à 17,3\% (95\% intervalle de crédibilité [ICr] 8,1 \% à $30 \%$ ), 10,5\% (95\% ICr 2,9\% à $23,7 \%$ ) et 3,2\% (95\% ICr 0,01\% à 19,8\%), respectivement. Le taux d'utilisation des ressources de santé au bout de 30 jours était de 1,7\%, puisque $0,95 \%$ des participants avaient recouru aux services d'un médecin. Aucun prédicteur d'occurrence d'ÉIM n'a été déterminé.

EXPOSÉ : L'incidence d'ÉIM était plus élevée dans les 48 heures suivant la coloscopie et très basse au bout de deux semaines, ce qui appuie la recommandation d'évaluer les complications tardives au quatorzième jour, émise par l'Association canadienne de gastroentérologie. Les prédicteurs de nouveaux ÉIM n'ont pas été établis, mais les vastes ICr n'écartaient pas la possibilité d'associations. Même si moins de $1 \%$ des participants déclaraient avoir consulté un médecin en raison d'ÉIM, ce résultat peut représenter un nombre substantiel de rendez-vous, car de plus en plus de coloscopies sont effectuées chaque année.

CONCLUSION : Les ÉIM sont courantes après la coloscopie, surtout dans les deux semaines suivant l'intervention, mais nécessitent peu de ressources de santé.
In Canada, colorectal cancer (CRC) is the second leading cause of cancer death and the fourth most common cancer diagnosed overall (1). It is possible to decrease the mortality related to CRC by screening, which is now recommended for all Canadians 50 through 75 years of age who are at average risk for developing CRC (ie, no personal or familiar risk factors other than age) (2). For most individuals, CRC screening begins with stool testing, followed by colonoscopy when the stool test is positive. Colonoscopy is the recommended modality for individuals at higher risk for CRC including those with a family history of CRC or personal history of polypectomy (3-5). While many Canadian provinces have implemented organized screening programs in the past three years, including quality assurance structures aimed at

${ }^{1}$ Division of Gastroenterology, Vancouver General Hospital, Vancouver, British Columbia; ${ }^{2}$ Department of Medicine; ${ }^{3}$ Department of Epidemiology,

Biostatistics and Occupational Health, McGill University, Montreal, Quebec

Correspondence: Dr Maida J Sewitch, 687 Pine Avenue West, V Building, Room V2.15, Montreal, Quebec H3A 1A1

Telephone 514-934-1934 ext 44736, fax 514-934-8293, e-mail maida.sewitch@mcgill.ca

Received for publication June 6, 2014. Accepted November 7, 2014 
ensuring delivery of high standard care (6), most CRC screening in the province of Quebec is peformed opportunistically.

Extensive research and recommendations have been made to enhance the quality of all colonoscopies. The resulting quality indicators have focused primarily on physician performance (adenoma detection rate, cecal intubation rate and colonoscope withdrawal time) and safety (serious adverse events rate). As interest in the patient-centred care model shifts attention to patient satisfaction and comfort $(7,8)$, information regarding the incidence of minor adverse events (MAEs), which do not result in hospitalization but cause significant discomfort, becomes important. To date, the few studies that have addressed MAEs after colonoscopy have reported rates that vary from $16.6 \%$ to $40.7 \%(9-15)$. These studies were heterogeneous in terms of the definitions of MAEs and the time points for their evaluation. Some studies failed to indicate the indication for colonoscopy (screening/nonscreening); calculate the MAE rates according to the endoscopic procedure (gastroscopy or colonoscopy); report the performance of intracolonoscopy procedures (polypectomy, biopsy) that could increase the risk of adverse events; and evaluate the presence of the discomfort before colonoscopy. In other studies, recall bias may have influenced the estimated rates, especially for lengthy follow-up intervals. Conducting a longitudinal study that includes short, medium and lengthy follow-up would not only provide better estimates of the rates and nature of MAEs, it would also yield information as to when these events occur.

Increasing our knowledge of the health resources used for postcolonoscopy MAEs would be helpful in decreasing unnecessary utilization. However, data are scant and substantial variability exists in the services assessed $(12,13,16)$. Some studies included visits to the emergency department but did not include visits to primary care physicians, walk-in clinics or telephone consultations (16). In contrast, other studies considered visits to the emergency department as serious adverse events independent of the final discharge diagnosis $(12,13)$, or relied on diagnosis and procedure codes (ie, International Classification of Diseases, Ninth and 10th Revisions) that would not capture MAEs.

Thus, the purpose of the present study was to estimate the rates and nature of incident MAEs at three assessment time points and 30-day cumulative incidence following outpatient colonoscopy, and the rate of health care resources use (visits to the emergency department, primary care doctor or gastroenterologist, and consultations with nurse(s), pharmacists or use of a telephone hotline) that resulted from MAEs. A secondary aim was to identify factors associated with the 30-day cumulative incidence of MAEs.

\section{METHODS}

\section{Data collection}

A longitudinal cohort study was conducted at the Montreal General Hospital (Montreal, Quebec). Eligible individuals were 40 to 76 years of age, scheduled for an outpatient colonoscopy, able to communicate in English or French, and provide informed consent. Individuals 40 to 50 years of age had to have a positive family history of CRC for whom the recommendation was to begin CRC screening at 40 years of age with colonoscopy $(3,5)$.

Individuals were excluded if they were scheduled for a sigmoidoscopy, proctoscopy or same-day gastroscopy, had an active history of $\mathrm{CRC}$, or were under investigation for a possible flare of known inflammatory bowel disease. Ethics approval was obtained from the McGill University Faculty of Medicine Institutional Review Board (Montreal, Quebec) before study inception, and all participants provided written informed consent.

Five trained research assistants were responsible for recruitment, administration of the baseline questionnaire, review of endoscopy reports and telephone follow-up. The baseline questionnaire collected data regarding medical history (diabetes, heart conditions, pulmonary diseases, kidney disease, liver disease, neurological conditions, inflammatory bowel disease), use of high-risk medications for colonoscopy outcomes (acetylsalicylic acid, clopidogrel [Plavix, sanofi, USA], dabigatran, warfarin (Coumadin, Bristol-Myers Squibb, USA) ticagrelor, prasugrel and nonsteroidal anti-inflammatory drugs), presence of symptoms in the 30 days before the colonoscopy (abdominal pain, bloating, diarrhea, constipation, nausea or vomiting, blood in the stools, rectal or anal pain, headaches or migraine, other symptoms) and demographics (age, sex, ethnicity, smoking status, level of education). The endoscopy report provided data on the physician performing the colonoscopy, trainee participation during the index colonoscopy (yes/ no), colonoscopy indication (screening/not screening), doses of midazolam (mg) and fentanyl ( $\mu \mathrm{g})$ used, physician's evaluation of bowel preparation quality (excellent, good, fair/poor), performance of biopsy or polypectomy (yes/no), method of colon insufflation (air/carbon dioxide) and duration of the colonoscopy ( $\mathrm{min}$ ).

For the purpose of the present study, screening colonoscopy was defined as a procedure performed in asymptomatic individuals 50 to 76 years of age (2). The presence/absence of symptoms was derived from the baseline questionnaire and the endoscopy report. Nonscreening colonoscopy was defined as one performed for investigation of gastrointestinal symptoms, dysplasia detection in inflammatory bowel disease, iron deficiency anemia; follow-up to resolution of an episode of acute diverticulitis, past polypectomy, surgically removed CRC, positive nonendoscopy CRC screening test (eg, fecal immunochemical test, fecal occult blood test, virtual colonoscopy, doublecontrast barium enema); or family history of CRC.

Follow-up occurred by telephone interview, or e-mail and Internetbased survey at three time points: two, 14 and 30 days after the colonoscopy. The questions were exactly the same for the two modes of data collection. When participants were not reached, they were telephoned daily for the next three consecutive days (one attempt per day). When participants were not reached on the same day but within the next three consecutive days, the MAE was recorded as having occurred at that assessment time point. If the participant remained unreachable, the research assistants waited until the next scheduled follow-up to contact them again. Similarly, e-mails were sent for follow-ups, and a reminder e-mail daily for the next three consecutive days for nonresponse. The surveys were created using the Survey Monkey Internet service (www.surveymonkey.net).

MAE was defined as any discomfort the patient experienced after discharge home from the endoscopy unit that did not require any of the following: an overnight stay in the emergency room; hospitalization, blood product transfusion, prescription of antibiotics, surgical or endoscopic intervention or caused death, and that was not present in the 30 days before the colonoscopy as reported in the baseline questionnaire. Data regarding the nature of the discomfort (abdominal pain, bloating, diarrhea, constipation, nausea or vomiting, blood in the stools, rectal or anal pain, headaches or migraine or other symptoms) were obtained. The participant was asked about consulting a health professional/service for the discomfort, the type of professional/service consulted (Info-Santé Help Line, emergency room physician, family doctor, gastroenterologist, nurse, pharmacist or other professional), and whether the patient was hospitalized or received a blood transfusion. Predictors of MAEs were determined a priori based on previous studies, and included age $(9,12)$, sex $(12,13)$, presence of comorbidities (10), performance of a polypectomy $(13,14)$, colonoscopy duration (13), trainee participation $(10,12)$ and modality of colon insufflation $(17)$. Information regarding the independent variables was obtained from the baseline questionnaire and the endoscopist report.

\section{Statistical analysis}

Description of the study population at entry included means and SDs for continuous data and frequency distributions for categorical data. The descriptive analyses were performed using STATA/SE version 11.2 (StataCorp, USA). Bayesian binomial hierarchical modelling was used to estimate the MAE rates in the cohort to account for patient clustering within physicians (18). Incident MAE rates at each assessment time point were calculated as the sum of individuals who reported at least one MAE at that time point. The 30-day cumulative incidence 
MAE rate was calculated as the sum of all individuals who reported at least one MAE at any follow-up. Normal noninformative priors for all parameters were used. Univariate and multivariate logistic regression were used to identify factors associated with the 30-day cumulative incidence MAE rate. Missing data for independent variables were handled using multiple imputation. Bayesian analyses were performed using WinBUGS version 1.4.3 (MRC Biostatistics Unit, United Kingdom).

\section{Sample size}

The sample size calculation was based on the estimate of MAEs at seven days according to Ko et al (13). The proportion of patients with at least one MAE at two days was expected to be $34 \%$, the aim was to estimate this proportion to an accuracy of $\pm 5 \%$ using a $95 \%$ CI. This criterion suggested that 345 participants needed to be recruited. An $20 \%$ attrition rate was expected based on the completion rate observed in similar studies $(10,13,14)$. Thus, a total of 414 participants was needed to attain the desired level of accuracy.

\section{RESULTS}

\section{Recruitment}

Of the 705 consecutive patients approached for participation, 451 (64\%) eligible individuals accepted. After excluding 31 individuals (protocol violations, improper consent, age $<40$ or $>76$ years, concomitant gastroscopy, scheduled for a sigmoidoscopy, scheduled for an endoscopic ultrasound), the final sample size was 420 . Response rates for the day 2, 14 and 30 follow-ups were $342(81.4 \%), 335(79.8 \%)$ and $310(73.8 \%)$, respectively. In total, $268(63.8 \%)$ participants responded to all followups and $378(90.0 \%)$ responded to at least one follow-up.

\section{Participant and endoscopy characteristics}

Table 1 summarizes participant and endoscopy characteristics. Participants were a mean $( \pm$ SD) $58.7 \pm 8.3$ years of age and $192(45.7 \%)$ were female. Ninety-five $(22.6 \%)$ participants reported at least one comorbidity (diabetes $7.1 \%$, cardiac disease $5.2 \%$, pulmonary disease $4.8 \%$, inflammatory bowel disease $3.8 \%$, kidney disease $2.6 \%$, liver disease $1.4 \%$ and neurological disease $1.9 \%)$, and $89(21.2 \%)$ reported regular use of at least one high-risk medication (acetylsalicylic acid $16.2 \%$, nonsteroidal anti-inflammatory drugs $4.1 \%$, clopidogrel $0.7 \%$, warfarin [Coumadin, Bristol-Myers Squibb]/dabigatran 0.7\%). Of all colonoscopies, $302(71.9 \%)$ were performed by eight gastroenterologists and $118(28.1 \%)$ by five general surgeons. Trainees participated in $30(7.2 \%)$ colonoscopies. The 13 endoscopists performed between four and 80 (median 26) colonoscopies, and 10 reported carbon dioxide as the method of bowel insufflation. The endoscopy report was available for $418(99.2 \%)$ participants. The cecal intubation rate was $96 \pm 0.2 \%$ and the polypectomy rate was $34 \pm 0.47 \%$.

\section{MAE rates}

The day 2 follow-up occurred 2.6 \pm 0.99 days after the index colonoscopy. Of the 342 respondents, 59 reported at least one MAE, corresponding to an incident MAE rate of $17.3 \%$ (95\% credible interval [CrI] $8.1 \%$ to $30 \%$ ). The day 14 follow-up occurred $14.7 \pm 0.99$ days after the index colonoscopy. Of the 335 respondents, 33 reported at least one MAE, yielding an incident MAE rate of $10.5 \%$ (95\% CrI $2.9 \%$ to $23.7 \%$ ). The 30 -day follow-up occurred $30.7 \pm 1.07$ days after the index colonoscopy. Of the 310 respondents, six reported at least one MAE, yielding an incident MAE rate of $3.2 \%$ (95\% $\mathrm{CrI} 0.01 \%$ to $19.8 \%)$. Of the 378 (90\%) individuals who responded to at least one follow-up, 88 reported at least one MAE, corresponding to a 30-day cumulative incidence MAE rate of $23.3 \%$ (95\% CrI 19.1\% to $27.6 \%$ ). Eight (1.9\%) respondents reported a different symptom at a different assessment time point, and contributed only to the MAE rate for the earlier assessment time point. Table 2 summarizes the discomfort experienced at all three assessment time points. Abdominal pain and bloating were the most commonly reported symptoms at day 2 and day 14 , while abdominal pain and constipation were the most commonly reported symptoms at day 30 .
TABLE 1

Baseline patient and colonoscopy characteristics of the study population $(n=420)$

\begin{tabular}{|c|c|}
\hline Patient characteristic & \\
\hline Age, years mean $\pm S D$ & $58.7 \pm 8.3$ \\
\hline Female sex & $192(45.7)$ \\
\hline \multicolumn{2}{|l|}{ Preferred contact method } \\
\hline E-mail & $267(63.6)$ \\
\hline Telephone & $153(36.4)$ \\
\hline Comorbidities & $95(22.6)$ \\
\hline High-risk medications & $89(21.2)$ \\
\hline \multicolumn{2}{|c|}{ Symptoms in the 30 days before colonoscopy $(n=418)$} \\
\hline Any symptom & $237(56.4)$ \\
\hline Abdominal pain & $73(17.4)$ \\
\hline Bloating & $107(25.5)$ \\
\hline Diarrhea & $56(13.3)$ \\
\hline Constipation & $81(19.3)$ \\
\hline Nausea/vomiting & $32(7.6)$ \\
\hline Blood in stools & $39(9.3)$ \\
\hline Rectal pain & $40(9.5)$ \\
\hline Headache/migraine & $77(18.3)$ \\
\hline Other & $57(13.6)$ \\
\hline \multicolumn{2}{|l|}{ Ethnic background } \\
\hline White & $367(87.4)$ \\
\hline Nonwhite & $53(12.6)$ \\
\hline \multicolumn{2}{|l|}{ Endoscopy characteristics } \\
\hline \multicolumn{2}{|l|}{ Colonoscopy indication } \\
\hline Screening & $200(47.6)$ \\
\hline Not screening & $220(52.4)$ \\
\hline Fentanyl dose, $\mu \mathrm{g}$, mean $\pm \mathrm{SD}$ & $83.6 \pm 35.9$ \\
\hline Midazolam dose, mg, mean \pm SD & $3.1 \pm 1.3$ \\
\hline Endoscopy duration, min, mean \pm SD & $21.7 \pm 7.8$ \\
\hline Trainee participation & $30(7.2)$ \\
\hline \multicolumn{2}{|l|}{ Method of colon insufflation } \\
\hline Air & $100(24)$ \\
\hline Carbon dioxide & $320(76)$ \\
\hline Cecal intubation, $\%$, mean \pm SD & $96 \pm 0.2$ \\
\hline \multicolumn{2}{|l|}{ Preparation quality } \\
\hline Excellent or good & $372(88.6)$ \\
\hline Poor or fair & $44(10.5)$ \\
\hline
\end{tabular}

Data presented as $n$ (\%) unless otherwise indicated. *Versed (Roche, USA)

Table 3 presents the results of the univariate and multivariate logistic regression models used to estimate the effect of participant and endoscopy characteristics on the 30-day incidence of MAE. No associations were found, although wide CrIs throughout preclude definitive conclusions.

Health resource utilization

Table 4 presents the health resources used in the 30 days following colonoscopy. Seven $(1.7 \%)$ participants reported consulting a health professional for an MAE, four of whom consulted a physician. In addition, two participants reported experiencing a serious adverse event; each had visited the emergency department and required hospitalization for syncope and hemothorax (day 2 follow-up) and for postpolypectomy bleeding (day 30 follow-up).

\section{DISCUSSION}

The present longitudinal cohort study reports on the incidence, nature and predictors of outpatient postcolonoscopy MAEs. The incidence of MAEs was highest in the first $48 \mathrm{~h}$ following colonoscopy and 
TABLE 2

Frequency of incident* minor adverse events reported at days 2, 14 and 30 postcolonoscopy

\begin{tabular}{lccc}
\hline & \multicolumn{3}{c}{ Assessment time point } \\
\hline Minor adverse event & Day $\mathbf{2}(\mathbf{n}=\mathbf{3 4 2})$ & Day $\mathbf{1 4}(\mathbf{n}=\mathbf{3 3 5})$ & Day $\mathbf{3 0}(\mathbf{n = 3 1 0})$ \\
\hline Abdominal pain & $30(8.6)$ & $14(4.1)$ & $3(0.9)$ \\
Bloating & $22(6.3)$ & $17(5.0)$ & $0(0)$ \\
Diarrhea & $9(2.6)$ & $6(1.8)$ & $1(0.3)$ \\
Constipation & $9(2.6)$ & $7(2.1)$ & $3(0.9)$ \\
Nausea/vomiting & $6(1.7)$ & $2(0.6)$ & $0(0)$ \\
Blood in the stools & $2(0.6)$ & $2(0.6)$ & $0(0)$ \\
Rectal/anal pain & $9(2.6)$ & $1(0.3)$ & $2(0.6)$ \\
Headache & $13(3.7)$ & $2(0.3)$ & $0(0)$ \\
Other & $20(5.8)^{\dagger}$ & $7(2.1)^{\ddagger}$ & $1(0.3)$ \\
Any & $59(17)$ & $33(9.7)$ & $6(1.9)$ \\
\hline
\end{tabular}

Data presented as $n(\%)$. *Defined as no report in the 30 days before colonoscopy; IIncludes fatigue, dizziness, fever, shivers, nasal irritation, pain at venopuncture site, dehydration, back pain and anxiety; IIncludes disorientation, fatigue, itchiness, fever and dehydration; 'reaction to anesthesia' does not total to 100 because more than one symptom could be reported

TABLE 3

Univariate and multivariate results for predictors of 30-day cumulative incidence of minor adverse events

\begin{tabular}{lccc}
\hline & Univariate & & Multivariate \\
\cline { 2 - 2 } Variable & OR $(95 \% \mathrm{Cl})$ & OR $(95 \% \mathrm{Cl})$ \\
Sex & $1.01(0.97-1.03)$ & & $0.99(0.97-1.02)$ \\
Female & Reference & & Reference \\
Male & $0.81(0.49-1.29)$ & & $0.81(0.49-1.27)$ \\
Medical problem & & & \\
No & Reference & & Reference \\
Yes & $1.60(0.89-2.66)$ & & $1.60(0.87-2.68)$ \\
Trainee participation & & & \\
No & Reference & & Reference \\
Yes & $0.57(0.14-1.41)$ & & $0.53(0.15-1.27)$ \\
Duration, min & $1.01(0.99-1.03)$ & & $1.01(0.99-1.04)$ \\
Polypectomy & & & \\
No & Reference & & Reference \\
Yes & $1.16(0.68-1.85)$ & & $1.13(0.64-1.85)$ \\
Insufflation with & & & \\
Air & Reference & & \\
Carbon dioxide & $0.88(0.41-1.58)$ & & \\
\hline
\end{tabular}

uncommon after 14 days. Abdominal pain and bloating were consistently the two most frequently MAEs reported at days 2 and 14, while abdominal pain and constipation were the most frequently reported at day 30 . No predictors of the 30-day cumulative incidence rate of MAE were identified. Less than $1 \%$ of respondents sought the services of a physician for an MAE.

Our 30-day incident MAE rate was similar to rates found in some studies (9-11), but substantially different from others (12-15). Zubarik et al $(14,15)$ conducted two studies. In one $(14)$, the MAE rate at 30 days $(16.6 \%)$ may have been underestimated due to recall bias and, in the other (15), the rate (36.6\%) included symptoms that occurred in the endoscopy unit recovery area before discharge as well as those that occurred up to 30 days postcolonoscopy. The $34 \%$ MAE rate at seven days reported by Ko et al (13) did not account for previous symptoms and is likely an overestimate of incident MAEs. Finally, de Jonge et al (12) reported an MAE rate of $40.7 \%$ at 30 days; however, the subanalysis that restricted MAEs to those definitely related to the colonoscopy
TABLE 4

Number of individuals who used health resources for minor adverse events according to assessment time point

\begin{tabular}{|c|c|c|c|}
\hline Health resource & Day 2 (n=342) & Day $14(n=335)$ & Day $30(n=310)$ \\
\hline Family physician & 2 & 0 & 1 \\
\hline Gastroenterologist & 0 & 1 & 0 \\
\hline Emergency department ${ }^{*}$ & 0 & 0 & 0 \\
\hline Pharmacist & 0 & 1 & 0 \\
\hline Nurse & 1 & 0 & 0 \\
\hline Info-Santé Help Line & 0 & 0 & 0 \\
\hline Other & $1^{\dagger}$ & 0 & 0 \\
\hline Any use & 4 & 2 & 1 \\
\hline
\end{tabular}

Data presented as $n$. *Two individuals visited the emergency department for serious adverse events and they are not counted in the minor adverse events; ${ }^{\dagger}$ Acupuncture

showed a rate of $29 \%$. Our 30-day incident MAE rate is lower than the sum of MAE rates at each assessment time point because patients who reported more than one MAE or at more than one assessment time point were counted only once in determining this rate.

We did not identify any predictors of new-onset MAEs, but wide CrIs meant that associations could not be ruled out. It is possible that the impact of polypectomy was diluted because we did not specify the method of polyp removal (eg, forceps or electrocautery-assisted); electrocautery has been associated with increased odds for MAEs (13). Contrary to a recent meta-analysis, the method of insufflation (air versus carbon dioxide) was not a predictor of postcolonoscopy discomfort in our study, possibly due to the lack of statistical power (17).

The evaluation of health care resources utilization for MAEs revealed that seven $(1.7 \%)$ participants had contacted a health professional, a finding that supports the belief that MAEs are generally mild and short lived. Our follow-up relied on direct contact with patients to learn about the consultations to physicians and other health professionals, which represent real-world health care resources use. Four $(0.95 \%)$ participants reported medical consultations; although this was a small percentage of our sample in the context of the large number of colonoscopies performed annually, it may represent a significant number of physician visits for MAEs. Some of these consultations may be avoided with a $24 \mathrm{~h}$ telephone follow-up because they were not avoided with the detailed discharge information that patients routinely received in the studied endoscopy unit.

Our findings showed that the majority of MAEs occur within $48 \mathrm{~h}$ after the colonoscopy and almost all occur within the first two weeks, supporting the Canadian Association of Gastroenterology's recommendation that late complications should be assessed at 14 days (19). Nevertheless, the timing for contacting the patient for colonoscopy follow-up is debatable and depends on the purpose of the assessment. If the purpose is to inquire about the patient's condition, satisfaction with the colonoscopy experience or to reinforce postdischarge instructions, then early follow-up (within two days) may be preferred. However, if the purpose is to monitor serious adverse events, then a longer time interval may be preferred. A population-based study by Rabeneck et al (20) found that a 14-day interval would capture the majority of bleeds requiring hospital admission. Similarly, we found that the majority of MAEs occurred within the first 14 days after colonoscopy. Our findings that polypectomy and/or comorbidities increase the risk for MAEs mirror those of others; these variables could be used to identify patients targeted for colonoscopy aftercare.

Our observational study had several limitations. Selection bias may have occurred if respondents were different from nonrespondents with regard to MAE occurrence. The endoscopic report software uses 'screening' as the default indication for colonoscopy, and this may have resulted in misclassification. However, we reviewed the patient's clinical history as summarized in the endoscopy report to classify the colonoscopy indication according to our definition. Limited generalizability 
of our findings is possible because the study was conducted in a large academic centre, where physicians had performed several thousand endoscopies. Finally, the small sample size produced very wide CrIs for predictors of MAEs precluding definitive conclusions.

\section{CONCLUSIONS}

Our study presents the first prospective estimates of incident MAE rates after outpatient colonoscopies. Our single-institution longitudinal findings provide empirical evidence on the timing and nature of MAE occurrence. Replication of our findings may be informative as to the type of after-care that could be implemented to avoid unnecessary physician consults.

FUNDING: This research was funded by the Fonds de recherche $d u$ Québec - Santé through an operating grant awarded to Maida Sewitch. Vladimir Azalgara MD, MSc was funded by the Research Institute of the McGill University Health Centre (RI-MUHC) through a RI-MUHC Master of Science studentship.

\section{REFERENCES}

1. Canadian Cancer Society. Canadian cancer statistics 2012. Toronto: Canadian Cancer Society, 2012.

2. Leddin DJ, Enns R, Hilsden R, et al. Canadian Association of Gastroenterology position statement on screening individuals at average risk for developing colorectal cancer: 2010.

Can J Gastroenterol 2010;24:705-14.

3. Levin B, Lieberman DA, McFarland B, et al. Screening and surveillance for the early detection of colorectal cancer and adenomatous polyps, 2008: A joint guideline from the American Cancer Society, the US Multi-Society Task Force on Colorectal Cancer, and the American College of Radiology. Gastroenterology 2008;134:1570-95.

4. Lieberman DA, Rex DK, Winawer SJ, et al. Guidelines for colonoscopy surveillance after screening and polypectomy: A consensus update by the US Multi-Society Task Force on Colorectal Cancer. Gastroenterology 2012;143:844-57.

5. Rex DK, Johnson DA, Anderson JC, et al. American College of Gastroenterology guidelines for colorectal cancer screening 2009 [corrected]. Am J Gastroenterol 2009;104:739-50.
6. Zarychanski R, Chen Y, Bernstein CN, et al. Frequency of colorectal cancer screening and the impact of family physicians on screening behaviour. CMAJ 2007;177:593-7.

7. Sewitch MJ, Dube C, Brien S, et al. Patient-identified quality indicators for colonoscopy services. Can J Gastroenterol 2013;27:25-32.

8. Sewitch MJ, Gong S, Dube C, et al. A literature review of quality in lower gastrointestinal endoscopy from the patient perspective. Can J Gastroenterol 2011;25:681-5.

9. Baudet JS, Diaz-Bethencourt D, Aviles J, et al. Minor adverse events of colonoscopy on ambulatory patients: The impact of moderate sedation. Eur J Gastroenterol Hepatol 2009;21:656-61.

10. Bini EJ, Firoozi B, Choung RJ, et al. Systematic evaluation of complications related to endoscopy in a training setting: A prospective 30-day outcomes study. Gastrointest Endosc 2003;57:8-16.

11. Chen YK, Godil A, Thompson SA, et al. Telephone callback is unnecessary after outpatient endoscopy. J Clin Gastroenterol 1998;26:342-3.

12. de Jonge V, Sint Nicolaas J, van Baalen O, et al. The incidence of 30-day adverse events after colonoscopy among outpatients in the Netherlands. Am J Gastroenterol 2012;107:878-84.

13. Ko CW, Riffle S, Shapiro JA, et al. Incidence of minor complications and time lost from normal activities after screening or surveillance colonoscopy. Gastrointest Endosc 2007;65:648-56.

14. Zubarik R, Fleischer DE, Mastropietro C, et al. Prospective analysis of complications 30 days after outpatient colonoscopy. Gastrointest Endosc 1999;50:322-8.

15. Zubarik R, Ganguly E, Benway D, et al. Procedure-related abdominal discomfort in patients undergoing colorectal cancer screening: A comparison of colonoscopy and flexible sigmoidoscopy. Am J Gastroenterol 2002;97:3056-61.

16. Leffler DA, Kheraj R, Garud S, et al. The incidence and cost of unexpected hospital use after scheduled outpatient endoscopy. Arch Intern Med 2010;170:1752-7.

17. Wang WL, Wu ZH, Sun Q, et al. Meta-analysis: The use of carbon dioxide insufflation vs. room air insufflation for gastrointestinal endoscopy. Aliment Pharmacol Ther 2012;35:1145-54.

18. Gelman A, Carlin J, Stern H, Rubin D. Bayesian Data Analysis, 2nd edn. Boca Raton: Chapman and Hall, 2003.

19. Armstrong D, Barkun A, Bridges R, et al. Canadian Association of Gastroenterology consensus guidelines on safety and quality indicators in endoscopy. Can J Gastroenterol 2012;26:17-31.

20. Rabeneck L, Saskin R, Paszat LF. Onset and clinical course of bleeding and perforation after outpatient colonoscopy:

A population-based study. Gastrointest Endosc 2011;73:520-3. 


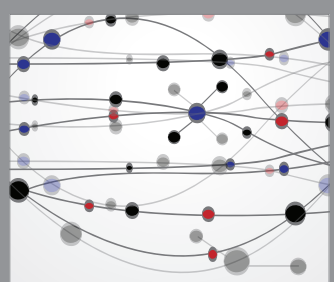

The Scientific World Journal
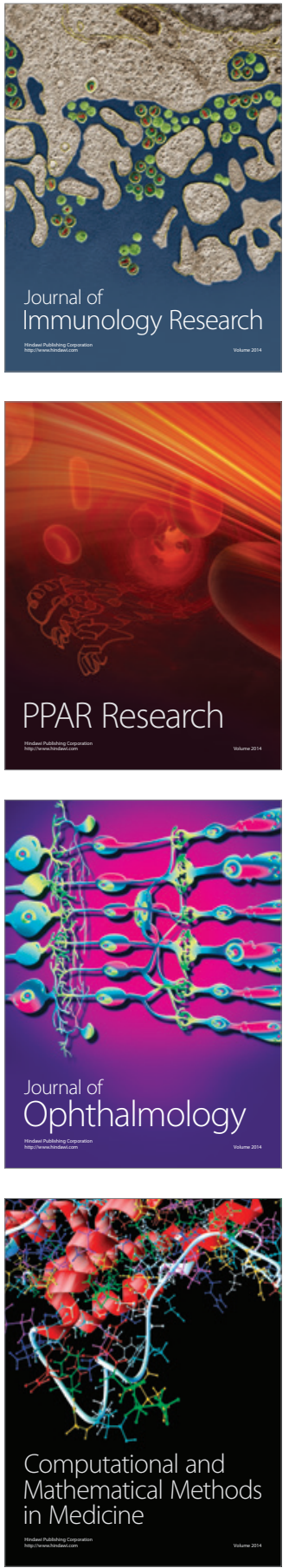

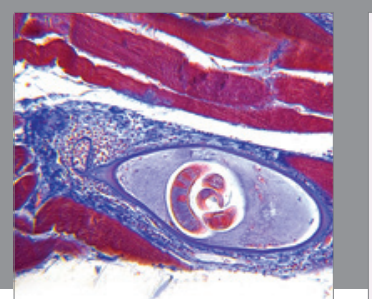

Gastroenterology Research and Practice

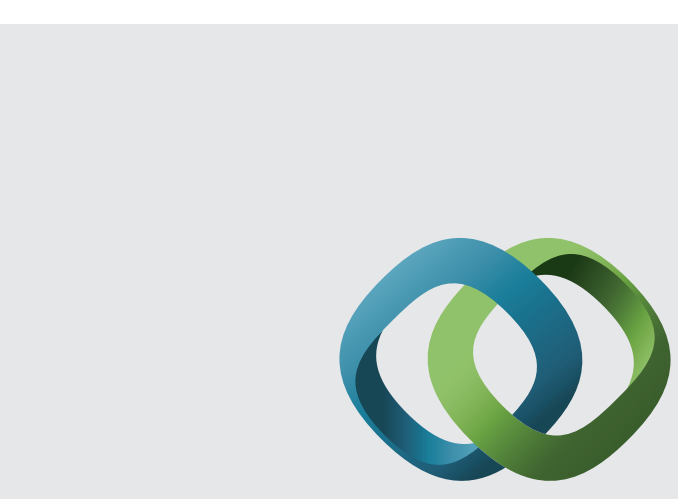

\section{Hindawi}

Submit your manuscripts at

http://www.hindawi.com
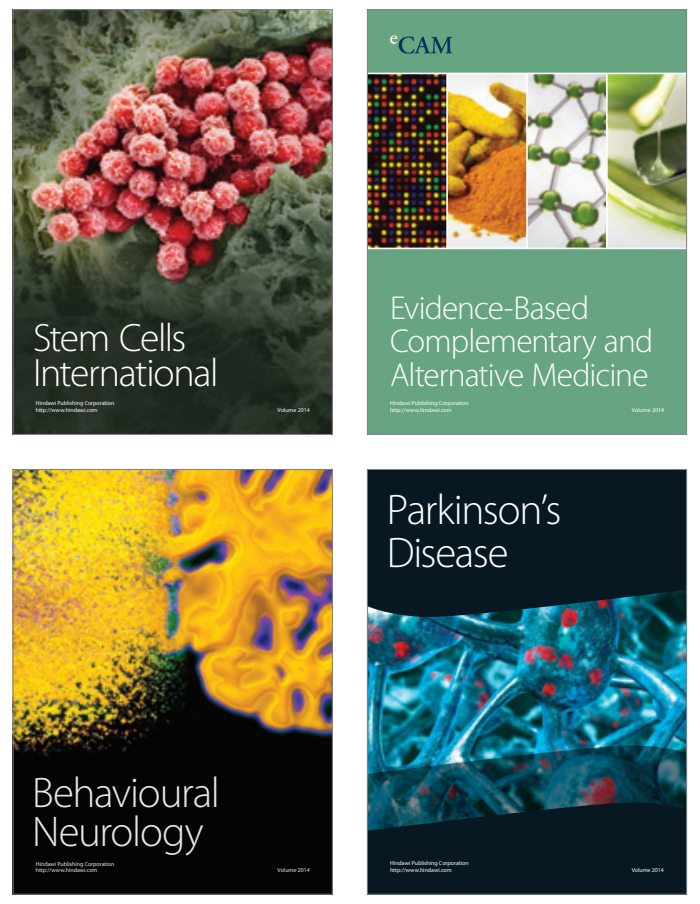
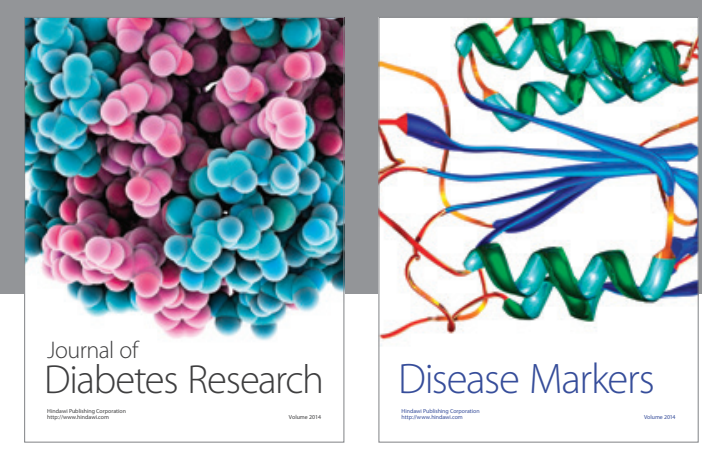

Disease Markers
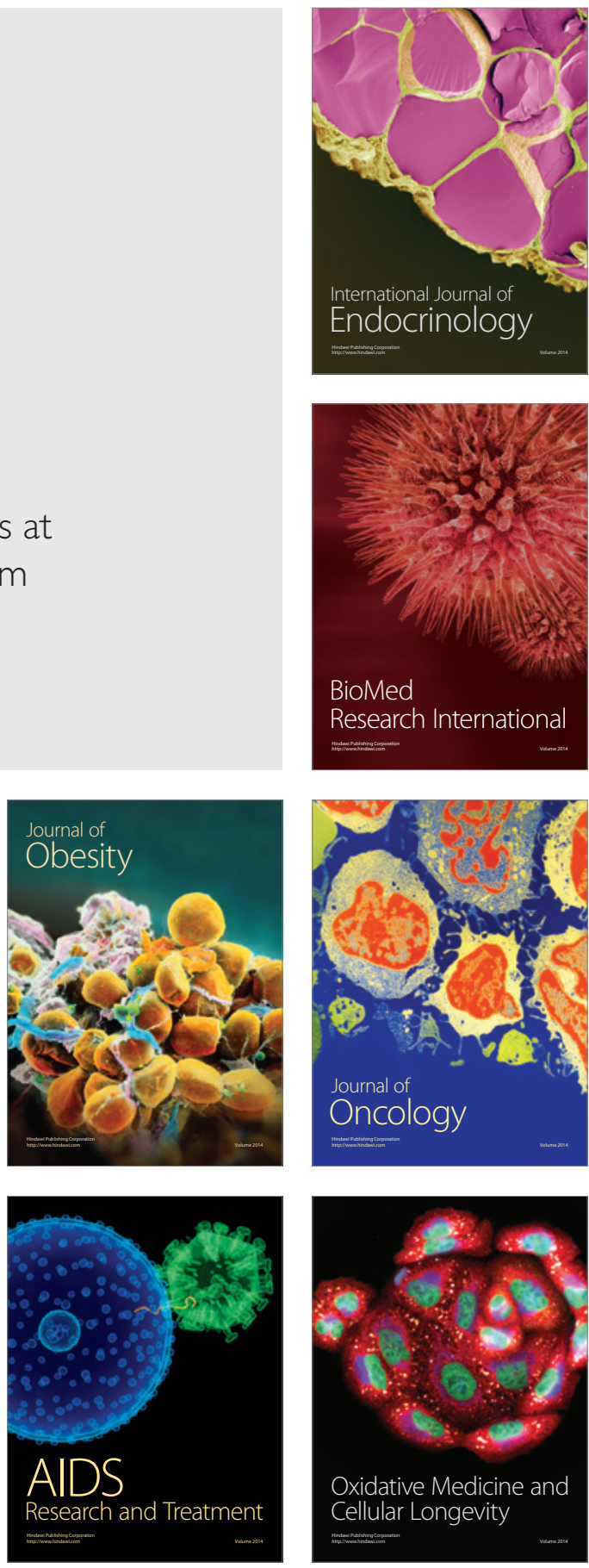